more enthesitis and peripheral arthritis. Enthesitis is initiated during a mechano-sensation and the cultural difference including style of footwear could probably be one of the factors explaining our findings inflammatory back pain has been reported to be higher in Indians compared to Caucasians which could be due to life style

The fact that ASDAS CRP behaves similarly in Indian patients across the two countries and is more when compared to Caucasians might point towards overall higher burden of disease in Indian population

To our knowledge this is a first study comparing clinical manifestations of SpA between Indians and Caucasians

References:

[1] Brown MAet al. Susceptibility to ankylosing spondylitis in twins: the role of genes, HLAand environment.Arthritis Rheum 1997;40: 1823-8

[2] J Simione, et al. Fecal Calprotectin, Gutlnflammation and SpA Archives of Medical Research. 2019;50:41-46

[3] http://www.ons.gov.uk/census

Disclosure of Interests: Nibha Jain: None declared, Sapan Pandya: None declared, Puja Srivastava: None declared, Prashant Chotalia: None declared, Arumugam Moorthy Speakers bureau: Abbvie, Novartis,UCB,MSD DOI: 10.1136/annrheumdis-2020-eular.6497

\section{AB0695 SUSTAINED ASDAS-CRP REMISSION IS ASSOCIATED WITH BETTER LONG-TERM FUNCTIONAL OUTCOMES: A REAL-LIFE ANKYLOSING SPONDYLITIS COHORT STUDY}

J. M. Kerber ${ }^{1}$, J. D. De Mello ${ }^{1}$, P. Palominos ${ }^{2}$, A. A. Gasparin², F. D. A. Menegat ${ }^{2}$, C. V. Brenol ${ }^{2}$, C. Kohem ${ }^{2}{ }^{1}$ Federal University of Rio Grande do Sul, Porto Alegre, Brazil; ${ }^{2}$ Hospital de Clínicas de Porto Alegre, Rheumatology Department, Porto Alegre, Brazil

Background: Ankylosing spondylitis (AS) leads to back pain and structural damage that may result in functional impairment ${ }^{1}$. Function is usually assessed in clinical trials conducted in developed countries, with patients receiving biological therapy ${ }^{2,3}$.

Objectives: To evaluate variation in the Bath Ankylosing Functional index (BASFI) over time in a AS cohort followed in a developing country. Compare the improvement in BASFI between patients achieving or not sustained ( $\geq 12$ months) ASDAS-CRP remission/low disease activity (LDA). Analyze predictors for achieving a minimum clinically important improvement (MCII) in BASFI $(\triangle \mathrm{BASFI} \leq-0.6)^{4}$.

Methods: This cross-sectional analysis was conducted in a retrospective cohort. Adult patients fulfilling the New York criteria for AS and followed during at least 5 years in the Spondyloarthritis clinic were included. BASFI variation ( $\triangle \mathrm{BASFI}$ ) was described as median $\left(25^{\text {th }} / 75^{\text {th }}\right)$. Comparison of $\triangle B A S F I$ between patients fulfilling or not sustained ASDAS-CRP remisson/LDA was done using the Mann-Whitney test. Hierarchical Poisson model was used to identify predictors for achieving a MCII in BASFI.

Results: 69 patients were analyzed, $53.6 \%$ were men, the mean age was $48.9 \pm 11.4$ years, and the mean follow-up time was $6.1 \pm 0.5$ years, median $\left(25^{\text {th }} / 75^{\text {th }}\right)$ disease duration of $10(5-18)$ years; $14.5 \%$ of the patients were on biological therapy at baseline. The median $\left(25^{\text {th }} / 75^{\text {th }}\right) \Delta$ BASFI was low: -0.1 $(-1.9 /+1.1)$ but $46.4 \%(\mathrm{~N}=32)$ presented a $\mathrm{MCll}$ in BASFI during follow-up. Patients who achieved sustained ASDAS-CRP remission/LDA had a significant improvement in BASFI over time compared with those who did not achieve this target $(p=0.026)$ (Figure 1). Patients with higher BASFI scores at baseline had a greater probability of achieving a MCII in BASFI (RR1.13 95\% CI 1.00-1.27 $\mathrm{p}=0.047$ ). Achieving and maintaining ASDAS-CRP remission/LDA during at least 12 months increased in $82 \%$ the probability to obtain a MCII in BASFI (RR 1.82 $95 \% \mathrm{Cl}$ 1.14-2.91, $\mathrm{p}=0.012)$.

Conclusion: Patients achieving sustained ASDAS-CRP remission/LDA had better functional outcomes over time compared to those not achieving this target. Higher BASFI scores at baseline and sustained ASDAS remission/LDA were predictors of a MCII in BASFI.

References:

[1] Madsen OR: Stability of fatigue, pain, patient global assessment and the Bath Ankylosing Spondylitis Functional Index (BASFI) in spondyloarthropathy patients with stable disease according to the Bath Ankylosing Spondylitis Disease Activity Index (BASDAI). Rheumatol Int. 2018;38(3):425-432.

[2] Baraliakos X, Kivitz AJ, et al: Long-term effects of interleukin-17A inhibition with secukinumab in active ankylosing spondylitis: 3-year efficacy and safety results from an extension of the Phase 3 MEASURE 1 trial. Clin Exp Rheumatol. 2018; 36(1):50-55

[3] Deodhar A, Reveille JD, et al: Safety and Efficacy of Golimumab Administered Intravenously in Adults with Ankylosing Spondylitis: Results through Week 28 of the GO-ALIVE Study. J Rheumatol. 2018; 45(3): 341-348

[4] Kviatkovsky MJ, Ramiro S, Landewé R, et al: The Minimum Clinically Important Improvement in Patient-acceptable Symptom State in the BASDAI and BASFI for Patients with Ankylosing Spondylitis. J Rheumatol 2016; 43(9): 1680-1686.

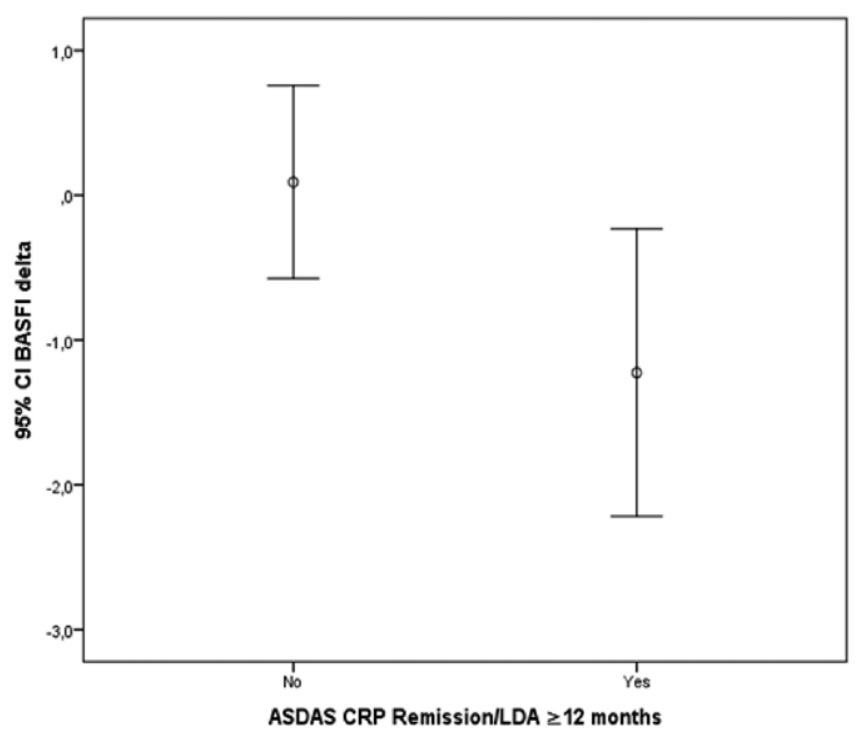

Figure 1. Comparison of $\triangle \mathrm{BASFI}$ between patients who achieved or not sustained ASDASCRP remission/LDA.

Disclosure of Interests: Juliana Maria Kerber Grant/research support from: This work was sponsored by the regional society of rheumatology (Sociedade de Reumatologia do Rio Grande do Sul)., Juliana Dias de Mello Grant/ research support from: This work was sponsored by the regional society of rheumatology (Sociedade de Reumatologia do Rio Grande do Sul)., Penelope Palominos Grant/research support from: This work was sponsored by the regional society of rheumatology (Sociedade de Reumatologia do Rio Grande do Sul)., Andrese Aline Gasparin Grant/research support from: This work was sponsored by the regional society of rheumatology (Sociedade de Reumatologia do Rio Grande do Sul)., Franciele de Almeida Menegat Grant/research support from: This work was sponsored by the regional society of rheumatology (Sociedade de Reumatologia do Rio Grande do Sul)., Claiton Viegas Brenol Grant/research support from: This work was sponsored by the regional society of rheumatology (Sociedade de Reumatologia do Rio Grande do Sul)., Charles Kohem Grant/research support from: This work was sponsored by the regional society of rheumatology (Sociedade de Reumatologia do Rio Grande do Sul).

DOI: 10.1136/annrheumdis-2020-eular.4555

\section{$\mathrm{AB} 0696$ \\ THE PATH OF A PATIENT WITH AXIAL SPONDYLOARTHRITIS TO DIAGNOSIS IN RUSSIA, DATA FROM THE EMAS SURVEY}

S. Lapshina ${ }^{1}$, M. Garrido-Cumbrera ${ }^{2}$, T. Dubinina ${ }^{3}$, A. Dubikov ${ }^{4}$, I. Gaydukova ${ }^{5}$, M. Korolev ${ }^{6}$, E. Zonova ${ }^{7}$, P. Pchelnikova ${ }^{8}$, A. Sitalo ${ }^{9}$, I. Shipilova ${ }^{10}{ }^{1}$ Kazan State Medical University, Kazan, Russian Federation; ${ }^{2}$ Universidad de Sevilla, Health and Territory Research (HTR), Sevilla, Spain;

${ }^{3}$ VA Nasonova Research Institute of Rheumatology, Moscow, Russian Federation; ${ }^{4}$ Clinic of Rheumatology, Vladivostok, Russian Federation; ${ }^{5}$ North-Western State Medical University n.a. II Mechnikov, Saint-Petersburg, Russian Federation; ${ }^{6}$ Novosibirsk State Medical University, Novosibirsk, Russian Federation; ${ }^{7}$ Research Institute of Clinical and Experimental Lymphology", Novosibirsk, Russian Federation; ${ }^{8}$ All-Russian Patient Union, Moscow, Russian Federation; ${ }^{9}$ Russian Ankylosing Spondylitis Association, 